\title{
Bilateral reductions in hippocampal volume in adults with epilepsy and a history of febrile seizures
}

William B Barr, Manzar Ashtari, Neil Schaul

\begin{abstract}
Objectives-To examine the degree and frequency of reductions in hippocampal volume in patients with temporal lobe epilepsy with and without a history of febrile seizures.
\end{abstract}

Methods-In vivo measures of hippocampal volume were computed from three dimensional gradient echo (FLASH) images in 44 patients undergoing comprehensive evaluations for epilepsy surgery. Twenty one patients $(48 \%)$ reported a history of febrile seizures. The volumes from these patients were compared with those from 23 patients without a history of febrile seizures and 34 healthy controls. Results-The febrile seizure group had significant reductions in volume, both ipsilateral (30\% decrease) and contralateral (15\% decrease), to the EEG seizure focus. Twelve of 18 patients with febrile seizures exhibited clinically significant ipsilateral volume reductions, defined as volumes falling 2 SD below the mean obtained from the control sample. Only four of 19 patients without febrile seizures exhibited this degree of reduction. No significant correlations were found between seizure variables (for example, duration of epilepsy, seizure frequency) and ipsilateral reductions in volume. However, a significant inverse correlation $(r=-0.45$, $P<0.05)$ between seizure frequency and the volume of the hippocampus contralat-

Division of Epilepsy and

Electroencephalography, Department of

Neurology,

Department of

Psychiatry,

Department of

Neurology, Long Island

Jewish Medical Center,

Long Island Campus

for the Albert Einstein

College of Medicine,

New Hyde Park, New

York, 10042, USA

W B Barr

M Ashtari

N Schaul

Correspondence to: Dr WB Barr, Hillside Hospital - Research, Long Island Jewish Medical Center, PO Box 38, Glen Oaks, NY 11004, USA

Received 7 May 1996 and in revised form 15 April 1997 Accepted 22 April 1997 eral to the seizure focus was found in the febrile seizure group.

Conclusion-These results suggest that a history of febrile seizures is associated with the finding of a smaller hippocampus on the side ipsilateral to the subsequent temporal lobe focus whereas chronic factors seem to be be related to pathology contralateral to the seizure focus.

(F Neurol Neurosurg Psychiatry 1997;63:461-467)

Keywords: epilepsy; hippocampus; febrile seizures

An accumulation of clinical evidence has indicated that optimal results from surgery for epilepsy are obtained in patients with neuronal loss and gliosis in tissue resected from the mesial temporal lobe. This pathology, variably labelled as mesial temporal or hippocampal sclerosis, is estimated to occur in $65 \%$ of the patients who undergo anterior temporal lobe resection. ${ }^{1}$ Despite its diagnostic importance, the aetiology and clinical correlates of hippocampal sclerosis remain poorly understood. Several investigators have reported a link between the presence of hippocampal sclerosis in adults and an early history of febrile seizures, although the causal nature of this relation remains unclear. ${ }^{2-6}$ It has not been determined whether hippocampal sclerosis is a direct result of febrile seizures or whether it is a cumulative effect of chronic seizures occurring throughout the lifespan. The question of whether hippocampal sclerosis is the "cause" or "effect" of seizures remains a controversial issue in epilepsy research. ${ }^{78}$

Previous investigations on the clinical correlates of hippocampal sclerosis have been limited to analyses of postsurgical or postmortem specimens. ${ }^{46910}$ Numerous technological developments have now made it possible to detect pathological changes associated with hippocampal sclerosis in vivo using advanced neuroimaging techniques. Magnetic resonance imaging is now used routinely in clinical settings to identify abnormal T2 signals or hippocampal atrophy that often signify hippocampal sclerosis. ${ }^{11}$ Research in this area has grown appreciably with the development of computer assisted morphometric techniques to provide reliable quantitative indices of hippocampal volume. Numerous studies using these methods have shown that lateralised EEG foci are accompanied by ipsilateral reductions in hippocampal volume. ${ }^{12-15}$ Relations between hippocampal volume and pathology, surgical outcome, and memory performance have also been examined. ${ }^{16-18}$ The largest unilateral reductions have been found in patients with a history of early onset seizures. ${ }^{19} 20$ The purpose of this investigation was to examine whether bilateral reductions in hippocampal volume may be associated with a history of febrile seizures.

\section{Methods}

SUBJECTS

Brain MR scans from 52 patients with focal temporal lobe seizures were selected from a consecutive series of 95 patients undergoing inpatient admissions for evaluation of intractable epilepsy. All 52 patients showed evidence of complex partial seizures of temporal lobe origin on combined EEG and video recordings during inpatient continuous intensive monitoring with surface and sphenoidal electrodes. ${ }^{21}$ 
EEG recordings with subdural or depth electrodes were used for localisation in a minority of cases. The 43 patients who were not selected for this study failed to meet these EEG criteria. Scans from seven of the 52 patients exhibited space occupying lesions on standard T2 clinical sequences. Those seven patients were also excluded from further analysis. A scan from one additional patient was excluded as a result of appreciable movement artifact.

The final sample consisted of 44 patients (22 men; 22 women) with a mean age of 33.0 (range 16-52) years. A total of 37 patients showed ictal and interictal EEG evidence of seizures originating from a unilateral temporal lobe focus (22 left temporal, 15 right temporal). The remaining seven patients showed EEG evidence of seizures originating independently from both temporal lobes.

Information regarding seizure history was obtained by more than one examiner and was confirmed from available medical records and at least one parent or family member. Age at first seizure was defined as the patient's first afebrile seizure. Onset of chronic seizures was defined as the age at which these seizures began to recur on a regular basis. A total of 21 patients $(48 \%)$ were found to have a history of febrile seizures, defined as seizures occurring during a pyrexial illness between the ages of 3 months and 5 years. ${ }^{22}$ Mean age at the occurrence of the initial febrile seizure was 13.6 (range 3-36) months. At least eight of these patients had symptoms meeting criteria for "complex" febrile seizures and five met criteria for "simple" febrile seizures. ${ }^{23}$ The remaining eight patients clearly had febrile seizures, although similar to other studies, reliable information regarding complex symptoms was unavailable.

A sample of 34 healthy subjects (18 men: 16 women) served as a normal control group. This group comprised a combination of hospital employee volunteers and subjects from a paid subject pool. All normal control subjects were screened for history of neurological disturbance including seizures. The mean age of the normal control group was 30.9 (range 17-48) years. The patient and normal control groups did not differ significantly in mean age or in sex distribution.

\section{IMAGE ACQUISITION}

Brain MRI was performed on a 1.0 Tesla whole body MR system (Siemens, Magnetom; Erlangen, FRG). The imaging protocol included a series of standard SE sequences in the axial and coronal orientations for clinical evaluation of neuropathological abnormalities. Additional coronal slices were collected perpendicular to the orbitomeatal line using a FLASH sequence with $40 \mathrm{~ms} / 15 \mathrm{~ms} / 1$ (TR/TE/Excitation), matrix size of $256 \times 256$, field of view of 300 $\mathrm{mm}$, and $50^{\circ}$ flip angle. This sequence provides 63 contiguous slices through the whole head with $3.1 \mathrm{~mm}$ thickness in 11 minutes. The hippocampus was visualised for morphometric analysis on eight to 10 of these coronal slices.
COMPUTERISED MENSURATION

All images were transferred from a VAX 11/750 to a SUN 3-160 workstation (Sun Microsystems, Mountainview, CA, USA) via magnetic tapes for offline computerised mensuration. Measurements of hippocampal volume were performed with a menu driven semiautomated computer mensuration system (Ektron Applied Imaging, Burlington, MA, USA). Hippocampal measurements were performed by manually tracing the outline of the structure with a mouse by depositing points along the border separating the hippocampus from surrounding tissue. The slice volume was calculated by multiplying the area by the slice thickness $(3.1 \mathrm{~mm})$ and the total hippocampal volume was calculated by summing the volumes of the contiguous slices.

Measures of hippocampal volume included the cornu ammonis, alveus, dentate gyrus, and subiculum. The border between the subiculum and the parahippocampal gyrus was defined as the most medial extent of the junction of the subiculum and parahippocampal gyrus. This border was delineated by extending a horizontal line through the medial pole of the temporal cortex. The anterior and posterior borders of the hippocampus were defined by invariant anatomical landmarks. All measurements began posteriorly at the level where the pulvinar is visualised and where the ascending fornix is first interrupted by the coronal sections. The anterior border of the hippocampus was defined as the slice caudal to the mammillary body. Measurements terminated at that point as it is difficult to differentiate the hippocampus from the amygdala in more anterior sections using FLASH MRI. The total hippocampal volume used in this study thus included about $80 \%$ of the total hippocampal formation. More detailed descriptions of these delineation criteria are provided in previous reports. $^{2425}$

All hippocampal volumes were measured by the same rater (MA) under blind conditions. The validity and reliability of the computer mensuration system and delineation criteria have been described. ${ }^{24}$ Previous analyses have disclosed an average measurement error of $2.5 \%$ between hippocampal volumes measured in MRI sections and those measured in postmortem sections with identical anatomical delineation criteria used in both samples. ${ }^{13}$

\section{STATISTICAL ANALYSIS}

Demographic variables were analysed with separate $t$ tests. Analyses of morphometric data were conducted on raw volumes. The effects of sex and height were examined as attempts at partial corrections for the effects of brain and body size. Differences between patient groups (left temporal $v$ right temporal $v$ MRI controls), sex differences, and differences between hippocampal volumes (left hippocampus $v$ right hippocampus) were tested by multivariate analysis of variance (MANOVA) using hippocampal volumes as repeated within subject dependent variable. ${ }^{26}$ The MANOVA is an analysis using multiple dependent variables that offers the advantage of analysing all effects 


\begin{tabular}{|c|c|c|c|c|c|c|c|c|c|c|}
\hline Group & No & $\operatorname{Sex}$ & $\begin{array}{l}\text { Age (y) } \\
\text { mean (SD) }\end{array}$ & $\begin{array}{l}\text { WAIS-R FSIQ } \\
\text { mean (SD) }\end{array}$ & $\begin{array}{l}\text { Height }(\mathrm{cm}) \\
\text { mean }(S D)\end{array}$ & $\begin{array}{l}\text { Age at 1st } \\
\text { non-febrile } \\
\text { seizures }(y) \\
\text { mean }(S D)\end{array}$ & $\begin{array}{l}\text { Duration of } \\
\text { epilepsy }(y) \\
\text { mean }(S D)\end{array}$ & $\begin{array}{l}\text { Seizure frequency } \\
\text { mean }(S D) \text { per } \\
\text { month }\end{array}$ & $\begin{array}{l}\text { Secondary } \\
\text { general } \\
\text { seizures }\end{array}$ & Seizure focus \\
\hline Feb+ & 21 & $6 \mathrm{M}, 15 \mathrm{~F}$ & $29.4(8.1)$ & 86.1 (11.3) & $167.8(9.6)$ & $9.8(8.7)$ & $19.6(8.9)$ & $8.6(9.1)$ & 15 & $11 \mathrm{~L}, 7 \mathrm{R}, 3 \mathrm{bi}$ \\
\hline Feb- & 23 & $16 \mathrm{M}, 7 \mathrm{~F}$ & $36.3(10.7)$ & $91.6(14.9)$ & $170.9(7.7)$ & $14.8(12.0)$ & $18.9(11.4)$ & $8.0(8.5)$ & 15 & $11 \mathrm{~L}, 8 \mathrm{R}, 4 \mathrm{bi}$ \\
\hline
\end{tabular}

simultaneously while reducing the probability of obtaining chance results from conducting multiple separate analyses (type I experimental error). Post hoc analyses with independent $t$ tests were conducted on variables showing significant main effects. Additional analyses were conducted using height as a covariate. The relations between hippocampal volume and seizure variables were examined with Pearson correlation coefficients. Two tailed tests with an $\alpha$ level of 0.05 were used in all analyses.

\section{Results}

The major result was that patients with a history of febrile seizures exhibited bilateral reductions in hippocampal volume when compared with other patients and controls. This finding was not the result of the unequal distribution of men and women among the groups. The greatest degree of volume reduction was found ipsilateral to the EEG seizure focus. These reductions were unrelated to seizure variables such as duration of epilepsy or frequency of seizures. A lesser degree of volume reduction was found in the hippocampus contralateral to the focus. These contralateral reductions were correlated with seizure frequency.

GROUP DIFFERENCES IN DEMOGRAPHIC AND SEIZURE VARIABLES

Table 1 shows the group means (SD) of demographic and seizure variables for patients with a history of febrile seizures $(\mathrm{Feb}+)$ and those without febrile seizures (Feb-). The groups differed significantly in sex distribution $\left(\chi^{2}=7.4, \mathrm{P}<0.01\right)$. Most of the $\mathrm{Feb}+$ group were women (15 of 21) but this trend was reversed in the Feb- group (seven of 23). Subject height was used as a gross index to examine the possibility of differences in hippocampal volume resulting from group differences in body size. Comparisons of height showed that, despite the significant sex effect, no significant systematic differences were found between the two groups. The $\mathrm{Feb}+$ group was significantly younger than the Feb- group $(t=2.41, \mathrm{P}<0.02)$. No group differences were found in mean intellectual functioning.
The Feb+ group's mean age at first febrile seizure was 13.6 (range 3-36) months. The Feb-group's mean age at the time of their first non-febrile seizure ever was 14.7 (range 1-50) years. The Feb+ group showed an earlier age at onset of chronic seizures, defined as the age when they began to experience seizures on a regular basis $(t=2.53, \mathrm{P}<0.02)$. There were no significant differences in the groups' mean duration of chronic epilepsy (current age minus age at onset of chronic seizures) as a result of the Feb+ patients' younger age at the time of this study. Further analyses disclosed that the groups were matched in recent seizure frequency and in the percentage of patients with complex partial seizures evolving to secondary generalised seizures. The percentage of patients with seizures originating from the left temporal lobe, right temporal lobe, or bitemporal regions was equivalent in the two groups.

\section{GROUP DIFFERENCES IN RIGHT AND LEFT} HIPPOCAMPAL VOLUME

Table 2 shows the mean left and right hippocampal volumes for men and women from the $\mathrm{Feb}+$, Feb-, and normal control groups. Group differences among these variables were assessed by MANOVA examining the effects of group, sex, and cerebral hemisphere. Sex was included as a factor to control for group differences that may be attributed to the unequal sex distributions in the Feb+ and Feb- groups. Significant results were limited to differences between groups $(\mathrm{Feb}+v \mathrm{Feb}-v$ normal control, $F=15.8, \mathrm{P}<0.001)$. There were no significant main effects or interaction effects involving differences between men and women or differences between the left and right hippocampi. The three way interaction between group, sex, and differences between left and right hippocampal volume was non-significant. The pattern of results did not change when height was used as a covariate. The lack of findings related to sex or height suggest that the current results are not a result of uncontrolled differences in sex or body size that may influence hippocampal volume measures.

Post hoc comparisons of group means disclosed that the significant group effect was

Table 2 Group means and confidence intervals for left and right hippocampal volumes by sex

\begin{tabular}{lllll}
\hline \multirow{2}{*}{ Group } & & & Hippocampal volume & \\
\cline { 4 - 5 } & Sex & No & Left mean (SD) $(95 \%$ CI) & Right mean (SD) (95\% CI) \\
\hline Feb+ & $\mathrm{M}$ & 6 & $1858.5(417.9)(1420-2297)$ & $2056.0(650.3)(1373-2739)$ \\
Feb- & $\mathrm{F}$ & 15 & $1784.7(497.2)(1509-2060)$ & $1783.3(382.3)(1572-1995)$ \\
Healthy controls & $\mathrm{M}$ & 16 & $2375.5(641.9)(2033-2718)$ & $2306.2(552.3)(2012-2601)$ \\
& $\mathrm{F}$ & 7 & $2281.7(458.2)(1882-2743)$ & $2461.9(834.7)(1688-3136)$ \\
& $\mathrm{F}$ & 18 & $2746.1(465.9)(2514-2978)$ & $2496.0(436.2)(2279-2713)$ \\
& 16 & $2568.9(481.7)(2312-2826)$ & $2511.8(454.6)(2270-2754)$ \\
\hline
\end{tabular}




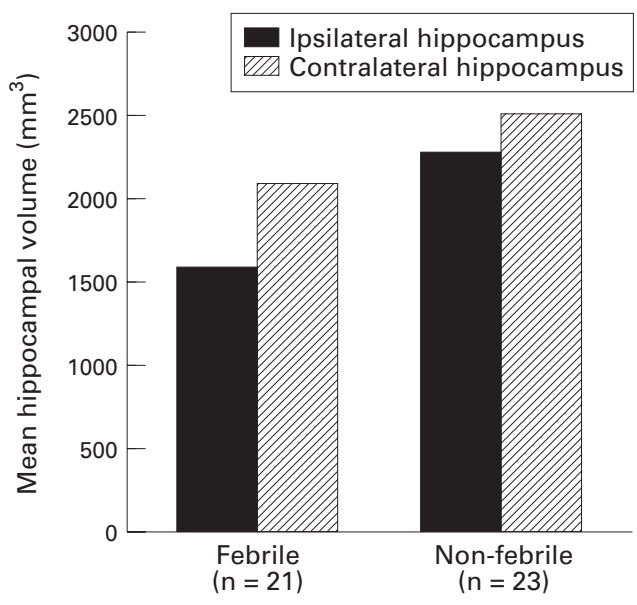

Hippocampal volumes ipsilateral and contralateral to the EEG focus for Feb+ and Feb-groups.

primarily the result of large bilateral volume reductions in patients with a history of febrile seizures. The Feb+ group showed significant left and right hippocampal volume reductions in comparison with normal controls $(\mathrm{P}<0.001)$ and in comparison with patients in the Febgroup $(\mathrm{P}<0.01)$.

GROUP DIFFERENCES IN HIPPOCAMPAL VOLUME IPSILATERAL AND CONTRALATERAL TO IDENTIFIED SEIZURE FOCUS

The relation between hippocampal volume and the side of the seizure focus was examined in a subsample of 37 patients with documented unilateral temporal lobe seizures. The right hippocampus was labelled as "ipsilateral" and the left hippocampus was labelled as "contralateral" in the 15 patients with right temporal lobe seizures. Conversely, the left hippocampus was labelled as "ipsilateral" and the right hippocampus was labelled as "contralateral" in the 22 patients with left temporal lobe seizures. Volumes from patients with right temporal lobe seizures and those with left temporal lobe seizures were combined for all analyses.

The figure shows the mean ipsilateral and contralateral hippocampal volumes for the $\mathrm{Feb}+$ and Feb- groups. These volumes were analysed by MANOVA using left and right hippocampi as the within subject dependent variables and group and sex as independent variables. The results of this analysis showed a significant main effect for group $(\mathrm{Feb}+v \mathrm{Feb}-$ $F=15.5, \mathrm{P}<0.001)$. Significant differences between the ipsilateral and contralateral hippocampi $(F=37.7, \mathrm{P}<0.001)$ and a significant interaction between group $(\mathrm{Feb}+v \mathrm{Feb}-)$ and hippocampus (ipsilateral $v$ contralateral) were also found $(F=5.7, \mathrm{P}<0.01)$. There were no significant main or interaction effects involving sex.

Table 3 Frequency of reductions for patients with unilateral seizure onset by group with $\geqslant$ $2 S D$ as criterion to define significant reduction

\begin{tabular}{llllll}
\hline & & \multicolumn{5}{l}{ Patients with significant hippocampal volume reductions (n) } \\
\cline { 4 - 7 } Group & No & No reductions & Ipsilateral only & Contralateral only & Bilateral reductions \\
\hline Feb+ & 18 & 5 & 12 & 0 & 1 \\
Feb- & 19 & 14 & 4 & 1 & 0 \\
\hline
\end{tabular}

The results of post hoc $t$ tests showed lower mean ipsilateral and contralateral hippocampal volumes in the Feb+ group (ipsilateral $t=3.8$, $\mathrm{P}<0.001$; contralateral $t=2.8, \mathrm{P}<0.008)$. In comparison with controls, the $\mathrm{Feb}+$ group exhibited mean volume reductions of the order of $30 \%$ on the side ipsilateral to the seizure focus and $15 \%$ on the side contralateral to the seizure focus. The mean contralateral hippocampal volume in the Feb- group was comparable with the total mean hippocampal volume from the normal control group (Feb- group mean 2454.1 (SD 466.5); normal control mean 2583.1 (SD 425.1). Within subject differences in hippocampal volume were examined with paired $t$ tests. The Feb+ group showed significant differences between the ipsilateral and contralateral hippocampus $(t=$ 4.29, $\mathrm{P}<0.001)$. These differences were not significant in the Feb- group ( $t=1.55$, NS).

Table 3 shows the number of patients exhibiting reductions in hippocampal volume. For clinical purposes, a significant reduction was defined as a volume with a value $>2$ SD below the control group mean. This conservative criterion is comparable with what is typically used to identify surgical candidates with unilateral volume reductions. ${ }^{12}$ All calculations were computed separately for males and females. A total of 12 of 18 patients from the Feb+ group showed significant reductions ipsilateral to the identified seizure focus. By contrast, only four of 19 patients from the Feb- group showed evidence of ipsilateral reductions in hippocampal volume $\left(\chi^{2}=7.8, P<0.01\right)$. Significant bilateral reductions were found in only one of the 21 patients from the Feb+ group. One of the 23 patients from the Feb- group showed a significant reduction in contralateral hippocampal volume. Only one of the 34 control subjects was identified as having any type of significant volume reduction.

RELATIONS BETWEEN HIPPOCAMPAL VOLUMES AND AGE AND SEIZURE VARIABLES

The relations among hippocampal volumes and age and seizure variables were examined with Pearson's correlations. Table 4 shows the correlation coefficients for the Feb+ and Febgroups. There were no significant correlations between hippocampal volumes and age, age of onset of afebrile seizures, or duration of chronic epilepsy. There was no relation between estimated seizure frequency and ipsilateral hippocampal volume. There was a significant correlation between estimated seizure frequency and contralateral hippocampal volume in the Feb+ group $(r=-0.45, \mathrm{P}<0.05)$, but not in the Feb- group.

\section{Discussion}

The results of this study indicate that adults with temporal lobe epilepsy and a history of febrile seizures tend to show significant reductions in hippocampal volume, both ipsilateral and contralateral to the EEG seizure focus. These reductions were found in comparison with measurements from healthy controls and patients with epilepsy and no history of febrile seizures. Patients with a history of febrile 
Table 4 Correlations among hippocampal volumes and seizure variables in 37 patients with unilateral temporal lobe seizures

\begin{tabular}{lllllc}
\hline Group & Side & Age & $\begin{array}{l}\text { Age at 1st non-febrile } \\
\text { seizure }\end{array}$ & $\begin{array}{l}\text { Duration of chronic } \\
\text { epilepsy }\end{array}$ & $\begin{array}{l}\text { Seizure } \\
\text { frequency }\end{array}$ \\
\hline Feb+ $(\mathrm{n}=18)$ & Ipsilateral hippocampus & -0.29 & -0.20 & -0.07 & -0.12 \\
Feb- $(\mathrm{n}=19)$ & Contralateral hippocampus & 0.03 & 0.17 & -0.14 & $-0.45^{\star}$ \\
& Ipsilateral hippocampus & -0.05 & 0.03 & -0.15 & -0.07 \\
& Contralateral hippocampus & -0.13 & 0.15 & -0.07 & 0.03 \\
\hline
\end{tabular}

$\star \mathrm{P}<0.05$

seizures showed a mean volume reduction of $30 \%$ in the hippocampus ipsilateral to the seizure focus and a mean reduction of $15 \%$ in the contralateral hippocampus. This pattern of bilateral reductions was seen in two thirds (12 of 18) of the patients with a history of febrile seizures. Significant unilateral volume reductions were seen in only four of 19 patients with no history of febrile seizures. The degree of ipsilateral volume reduction in the last group amounted to about $15 \%$ whereas the volume of the hippocampus contralateral to the seizure focus was comparable with measures obtained from the control group. There were no significant relations in any of the groups between the volume of the hippocampus ipsilateral to the seizure focus and variables such as age, duration of epilepsy, or estimated seizure frequency. There was, however, a significant relation between estimated seizure frequency and the volume of the hippocampus contralateral to the seizure focus in patients with a history of febrile seizures.

Reductions in hippocampal volume ipsilateral to the seizure focus have been described in different samples with various MRI methods. ${ }^{11}$ Our results are consistent with the results of other studies indicating that the greatest degree of volume reduction is seen in patients with a history of early onset seizures. ${ }^{1920}$ The current findings do not seem to be the result of uncontrolled differences in age, sex distribution, duration of epilepsy, or seizure control but are rather a result of some factor that is related to having febrile seizures in early childhood. Neuropathological correlates of reduced hippocampal volumes have been examined by several authors. ${ }^{171827}$ Results from these studies have confirmed that large unilateral volume reductions are associated with a pathological diagnosis of hippocampal sclerosis. However, it has also been shown that pathologically verified hippocampal sclerosis may exist without any evidence of any hippocampal atrophy when measured visually or with computerised measurement techniques. ${ }^{28}$

Most of the current methods for examining brain morphology in patients with chronic temporal lobe seizures (for example, histopathology or MR morphometry) emphasise the identification of unilateral neuronal loss or reduction in hippocampal volume ipsilateral to the EEG focus or side of surgery. ${ }^{12}{ }^{15}$ Interest in the hippocampus contralateral to the EEG focus has been minimal. The findings from the current study indicate that large (about 30\%) reductions in hippocampal volume ipsilateral to the EEG focus are often accompanied by lesser (about 15\%) reductions in the volume of the hippocampus contralateral to the seizure focus. This pattern of reductions was observed in most $(67 \%)$ of our patients with a history of febrile seizures and in less than one quarter $(21 \%)$ of our patients with no history of febrile seizures. The results of this study are similar to descriptions of a "diffuse" pattern of hippocampal volume loss in a recent MRI study of 20 patients with a history of febrile seizures. ${ }^{20}$ The frequency of bilateral reductions in volume in both of these samples is comparable with the frequencies of bilateral asymmetric hippocampal pathology that have been reported in postmortem samples. ${ }^{4929}$

The clinical significance of bilateral versus unilateral reductions in hippocampal volume remains to be determined. The current results suggest a link between bilateral pathology and febrile seizures, although it is clear that this relation is not seen in the entire sample. It is likely that many other aetiological factors play a part in the development of hippocampal sclerosis. Bilateral hippocampal volume loss has been reported in other samples, and are not always linked with a history of febrile seizures. ${ }^{3031}$ Free et al found bilateral volume reductions in $75 \%$ of their patients with a history of meningitis or encephalitis. ${ }^{31}$ The extent of bilateral reductions exceeded those in patients with a history of febrile seizures. The inconsistencies in the rates of bilateral volume reductions between these studies may be the result of differences in the composition of the samples or in the methods used to obtain and process the morphometric data.

The coexistence of large volume reductions ipsilateral to the seizure focus with lesser reductions contralateral to the focus in some patients raises the possibility that temporal lobe seizures may result in two distinct neuropathological processes. In 1966, Margerison and Corsellis made a distinction between pathology attributed to "classic" Ammon's horn sclerosis and pathology characterised as "end-folium" sclerosis. ${ }^{4}$ whereas the first traditionally involves hippocampal field CA1, the second is defined as "cell loss and gliosis confined essentially to the end folium". In their postmortem study of 55 cases, unilateral Ammon's horn sclerosis was identified in 18. A total of eight $(44 \%)$ of these cases had neuronal loss in the end folium on the opposite side. Cases with a diagnosis of Ammon's horn sclerosis were found to have the earliest age of onset. There were similar findings in a subsequent quantitative neuropathological study on surgical specimens by Sagar and Oxbury. ${ }^{6}$ These authors found that neuronal counts from hippocampal zone $\mathrm{H} 1$ (CA1), the end folium, and the dentate gyrus were reduced significantly in patients with a history of early onset seizures. A 
pattern described as "non-specific hippocampal sclerosis", consisting of moderate cell loss in $\mathrm{H} 1$ and the end folium, was found in patients with a long history of chronic seizures, but no history of early convulsions.

The relation between chronic epilepsy and febrile seizures is obviously complex since there is no simple one to one correspondence between the two phenomena. Most children who experience febrile seizures never develop chronic seizures. ${ }^{23}$ However, a history of febrile seizures is present in many adults with temporal lobe epilepsy who have such severe seizures that they are being considered for surgery. ${ }^{3233} \mathrm{~A}$ relation between febrile seizures and hippocampal pathology has been proposed on numerous occasions, but the mechanisms underlying the relation remain unclear. ${ }^{35435}$ Bratz and Sommer initially concluded that hippocampal sclerosis must play an important pathogenetic part in seizures. ${ }^{36}$ Some authors have argued that hippocampal sclerosis is a result of vascular or anoxic damage resulting from seizures or related to factors occurring at the time of birth. ${ }^{38-40}$ Others have hypothesised that it may be the result of prenatal factors that increase the risk of developing febrile seizures and subsequent hippocampal damage. ${ }^{2041}$ The debate is complicated further by the results of the experimental animal literature. Although it is clear that immature animals exhibit a lower threshold for evocation of seizures through mechanisms such as kindling or drug administration, ${ }^{42-44}$ these animals are also more resistant to the development of acute hippocampal pathology. ${ }^{44}$

Findings from this study indicate that patients with a history of febrile seizures exhibit large hippocampal volume reductions ipsilateral to the seizure focus that are independent of variables such as duration and seizure frequency. These same patients also exhibit a lesser degree of volume reductions contralateral to the seizure focus. These contralateral reductions in hippocampal volume correlate significantly with increasing seizure frequency. The pattern of findings are consistent with the description of two forms of hippocampal sclerosis proposed by Margerison and Corsellis. ${ }^{4}$ It is possible that the large reductions in ipsilateral volume typically identified through MR morphometry may be a consequence of an early pathological insult such as febrile seizures, whereas the lesser reductions on the contralateral side are the result of pathological effects induced by chronic seizures. Significant neuropathological changes, such as those associated with Ammon's horn sclerosis, may thus be the result of febrile seizures whereas less severe pathological changes, such as those seen in end folium sclerosis, may be the cumulative result of chronic recurrent seizures. Although the mechanisms underlying the relation between Ammon's horn sclerosis and febrile seizures remain unclear, there is evidence to suggest that status epilepticus or hyperthermic seizures during development produce hippocampal pathology that may or may not be apparent until maturity. ${ }^{46} 47$ There is also evidence that experi- mentally induced seizures result in a neuropathological condition resembling end folium sclerosis. ${ }^{48-50}$ It is thus conceivable that hippocampal sclerosis may be both a cause (Ammon's horn sclerosis) and an effect (end folium sclerosis) of chronic temporal lobe seizures.

This study provides additional findings that patients with chronic temporal lobe seizures, hippocampal reductions ipsilateral to the EEG focus, and a history of febrile seizures constitute a distinct diagnostic subgroup. ${ }^{51}$ Future MR studies may examine whether patients with bilateral interictal epileptiform phenomena and seizures arising independently from both temporal lobes exhibit greater reductions in bilateral hippocampal volume. It is important to note that the link between febrile seizures and hippocampal sclerosis has been established retrospectively in this study as well as in many others. The relation between hippocampal volume and simple versus complex febrile seizures should be examined in the future. Prospective longitudinal MR volumetric assessments of children who experience febrile seizures may provide important information for factoring out other genetic and environmental factors that make a person susceptible to developing neuropathological changes after febrile seizures.

WBB was supported by the Mental Health Clinical Research Center of Hillside Hospital, Long Island Jewish Medical Center, MH-41960 and by a Long Island Jewish Medical Center Faculty Research Award. The study was performed in association with The Brain Morphometry and Image Analysis Center supported by a grant from the Helen and Irving Schneider Family. We thank Dr Pierre Gloor and Dr Robert Bilder for their valuable comments on earlier drafts of this paper. This work was presented in part at the annual meeting of the American Epilepsy Society, Seattle, WA, 4-10 December 1992.

1 Babb TL, Brown WJ. Pathological findings in epilepsy. In: Engel J, ed. Surgical treatment of the epilepsies. New York: Raven Press, 1987:511-40.

2 Falconer MA. Genetic and related aetiological factors in temporal lobe epilepsy. Epilepsia 1971;12:13-31.

3 Falconer MA. Mesial temporal (Ammon's horn) sclerosis as a common cause of epilepsy: aetiology treatment and a common cause of epilepsy: aetiol
prevention. Lancet 1974;ii:767-770.

4 Margerison JH, Corsellis JAN. Epilepsy and the temporal Margerison JH, Corsellis JAN.
lobes. Brain 1966;89:499-530.

5 Lindsay J, Ounsted C, Richards P. Long-term outcome in children with temporal lobe seizures. I Social outcome and childhood factors. Dev Med Child Neurol 1979;21:285-98.

6 Sagar HJ, Oxbury JM. Hippocampal neuron loss in temporal lobe epilepsy: correlation with early childhood convulsions. Ann Neurol 1987;22:334-40.

7 Sutula TP. Experimental models of temporal lobe epilepsy: new insights from the study of kindling and synaptic reorganization. Epilepsia 1990;31 (suppl 3):S45-54

8 Gloor P. Mesial temporal sclerosis: historical background and an overview from a modern perspective. In: Lüders $\mathrm{H}$, ed. Epilepsy surgery. New York: Raven Press, 1991:689703 .

9 Sano K, Malamud N. Clinical significance of sclerosis of the cornu ammonis. Arch Neurol Psychiatr 1953;70:40-53.

10 Moritzen-Dam A. Hippocampal neuron loss in epilepsy and after experimental seizures. Acta Neurol 1982;66:601-42.

11 Kuzniecky RI, Jackson GD. Magnetic resonance in epilepsy. New York: Raven Press, 1995.

12 Jack CR, Sharbrough FW, Twomey CK, Cascino GD, Hirshorn KA, Marsh WR, et al. Temporal lobe seizures: lateralization with MR volume measurements of the hippocampal formation. Radiology 1990;175:423-9.

3 Ashtari M, Barr WB, Schaul N, Bogerts B. Threedimensional fast low-angle shot imaging and computerized volume measurement of the hippocampus in patients with chronic epilepsy of the temporal lobe. AFNR Am f Neuroradiol 1991;12:941-7.

14 Lencz T, McCarthy G, Bronen RA, Scott TM, Inserni JA, Sass KJ, et al. Quantitative magnetic resonance imaging in temporal lobe epilepsy: relationship to neuropathology and 5 Cook MJ, Fish DR, Shorvon SD, Straughan K, Stevens JM. Hippocampal volumetric and morphometric studies in frontal and temporal lobe epilepsy. Brain 1992;115:100115. 
16 Jack CR, Sharbrough FW, Cascino GD, Hirschorn KA, O'Brien PC, Marsh WR. Magnetic resonance image-based hippocampal volumetry: correlation with outcome after temporal lobectomy. Ann Neurol 1992;31:138-46.

17 Cascino GD, Jack CR, Parisi JE, Sharbrough FW, Hirschorn $\mathrm{KA}$, Meyer FB, et al. Magnetic resonance imaging-based volume studies in temporal lobe epilepsy: pathological correlations. Ann Neurol 1991;30:31-6.

18 Trenerry MR, Jack CR, Ivnik RJ, Sharbrough FW, Cascino GD, Hirschorn KA, et al. MRI hippocampal volumes and memory function before and after temporal lobectomy. Neurology 1993;43:1800-5.

19 Trenerry MR, Jack CR, Sharbrough FW, Cascino GD, Hirschorn KA, Marsh WR, et al. Quantitative MRI hippocampal volumes: association with onset and duration of epilepsy, and febrile convulsions in temporal lobectomy patients. Epilepsy Res 1993;15:247-52.

20 Kuks JBM, Cook MJ, Fish DR, Stevens JM, Shorvon SD. Hippocampal sclerosis in epilepsy and childhood febrile Hippocampal sclerosis in epilepsy

21 Schaul N, Barr WB, Decker RE. Summary of epilepsy surgery protocols: Long Island Jewish Medical Center. In: Luders H, ed. Epilepsy surgery. New York: Raven Press, 1992:802-3.

$22 \mathrm{NIH}$ Consensus Development Conference Summary Consensus statement on febrile seizures. Nelson KB, Ellenberg JH, eds. Febrile seizures. New York: Raven Press 1981:301-6.

23 Nelson KB, Ellenberg JH. Predictors of epilepsy in children who have experienced febrile seizures. N Engl f Med 1976 295:1029-33.

24 Ashtari M, Zito JL, Gold BI, Lieberman JA, Borenstein M, Herman PG. Computerized volume measurement of brain structure. Invest Radiol 1990;25:798-805.

25 Bogerts B, Ashtari M, Degreef G, Alvir J, Bilder RM, Lieberman JA. Reduced temporal limbic structure volumes on magnetic resonance images in first episode schizophrenia. Psychiatry Research: Neuroimaging 1990;35:1-13.

26 SPSS. SPSS/PC+ advanced statistics 4.0. Chicago: SPSS 1990.

27 Kim JH, Tien RD, Felsberg GJ, Osumi AK, Lee N, Friedman AH. Fast spin-echo MR in hippocampal sclerosis: correlation with pathology and surgery. AfNR Am F Neuroradiol 1995;16:627-36.

28 Jackson GD, Kuzniecky RI, Cascino GD. Hippocampal sclerosis without detectable hippocampal atrophy. Neurol ogy $1994 ; 44: 42-6$

29 Meencke HJ, Veith G. Hippocampal sclerosis in epilepsy. In Lüders H, ed. Epilepsy surgery. New York: Raven Press, 1992:705-15

30 King D, Spencer SS, McCarthy G, Luby M, Spencer DD. Bilateral hippocampal atrophy in medial temporal lobe epilepsy. Epilepsia 1995;36:905-10.

31 Free SL, Li M, Fish DR, Shorvon SD, Stevens JM. Bilateral hippocampal volume loss in patients with a history of encephalitis or meningitis. Epilepsia 1996;37:400-5.

32 Bruton CJ. The neuropathology of temporal lobe epilepsy. London: Oxford University Press, 1988.

33 Falconer MA, Taylor DC. Surgical treatment of drugresistant epilepsy due to mesial temporal sclerosis. Arch resistant epilepsy due
Neurol 1968;19:353-61.
34 Cavanaugh JB, Meyer A. Aetiological aspects of Ammon's horn sclerosis associated with temporal lobe epilepsy. BMf horn sclerosis asso

35 Mathieson G. Pathology of temporal lobe foci. In: Penry JK, Daly DD, eds. Advances in neurology. Vol 11. New York: Raven Press, 1975:163-85.

36 Bratz E. Ammonshornbefunde bei Epileptikern. Archives für Psychiatrie und Nervenkrankheiten 1899;31:820-35.

37 Sommer W. Erkrankumg des Ammonshorns als aetiologisches Moment der Epilepsie. Archives für Psychiatrie und Nervenkrankheiten 1880;10:631-75.

38 Spielmeyer W. The anatomic substratum of the convulsive state. Archives of Neurology and Psychiatry 1930;23:869-75.

39 Scholz W. The contribution of patho-anatomical research to the problem of epilepsy. Epilepsia 1959;1:36-55.

40 Earle KM, Baldwin M, Penfield W. Incisural sclerosis and temporal lobe seizures produced by hippocampal herniation at birth. Archives of Neurology and Psychiatry 1953;69: $27-42$.

41 Scheibel AB. Are coplex partial seizures a sequala of temporal lobe dysgenesis? In: Smith D, Treiman D, Trimble M, eds. Advances in neurology. New York: Raven Press, 1991: 59-77.

42 Moshe SL, Albala BJ. Maturational changes in postictal refractoriness and seizure susceptibility in developing rats. Ann Neurol 1983;13:552-7.

43 Lee S-S, Murata R, Matsuura S. Developmental study of hippocampal kindling. Epilepsia 1989;30:266-70

44 Albala BJ, Moshe SL, Okada R. Kainic acid induced seizures: a developmental study. Dev Brain Res 1984;13: 139-48.

45 Sperber EF, Haas KZ, Stanton PK, Moshßé $\beta$ SL. Resistance of the immature hippocampus to seizureinduced synaptic reorganization. Brain Res Dev Brain Res 1991;60:88-93.

46 Nohria V, Lee N, Tien RD, Heinz ER, Smith JS, Delong GR, et al. Magnetic resonance imaging evidence of hippocampal sclerosis in progression: a case report. Epilepsia 1994;35:1332-6.

47 Chisholm J, Kellogg C, Franck JE. Developmental hyperthermic seizures alter adult hippocampal benzodiazepine binding and morphology. Epilepsia 1985;26:151-7.

48 Sutula RS. Permanently altered hippocampal structure, excitability, and inhibition after experimental status epilepticus in the rat: The "dormant basket cell" hypothesis and its possible relevance to temporal lobe epilepsy. Hippocampus 1991;1:41-66.

49 Cavazos JE, Sutula TP. Progressive neuronal loss induced by kindling: a possible mechanism for mossy fiber synaptic reorganization and hippocampal sclerosis. Brain Res 1990; 527:1-6.

50 Cavazos JE, Das I, Sutula TP. Neuronal loss induced in limbic pathways by kindling: evidence for induction of hippocampal sclerosis by repeated brief seizures. F Neurosci 1994; 14:3106-21.

51 French JA, Williamson PD, Thadani VM, Darcey TM, Mattson RH, Spencer SS, Spencer DD. Characteristics of medical temporal lobe epilepsy. I. Results of history and physical examination. Ann Neurol 1993;34:774-80. 